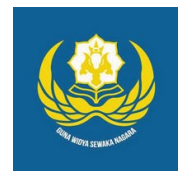

Jurnal Analogi Hukum

Journal Homepage: https://ejournal.warmadewa.ac.id/index.php/analogihukum

\title{
Pemanfaatan Tanah Pekarangan Desa di Desa Adat Gelgel Kabupaten Klungkung
}

\author{
Nyoman Andi Widjaya*, I Nyoman Gede Sugiartha dan Diah Gayatri Sudibya \\ Universitas Warmadewa, Denpasar-Bali, Indonesia \\ *andiwidjaya@gmail.com
}

\begin{abstract}
How To Cite:
Widjaya, N, A., Sugiartha, I, N, G., Sudibya, D, G. (2021). Pemanfaatan Tanah Pekarangan Desa di Desa Adat Gelgel Kabupaten Klungkung. Jurnal Analogi Hukum. 3 (2). 165-169. Doi: https://doi.org/10.22225/ah.3.2.2021.165-169
\end{abstract}

\begin{abstract}
Land can be a very basic human desire. The relationship between humans and land can be in the form of a non-secular occult relationship which more or less contains parts of mystical (mystical) powers as the embodiment of humans and their natural surroundings. Inquiry techniques are controlled by radio with knowledge gathering techniques through direct interviews with people who are competent in the theory of reception victimization, reception in complex theories in the construction of the rule of law to see contemporary phenomena in the order of people's lives, especially in the Gelgel environment of Purba Village, Klungkung Regency. The results showed that the use of the Village Grounds in the Purba Gelgel Village was freely leased by the residents of Gelgel Pakraman Village to different parties. The Sanctions of the Traditional Karma of the Gelgel Purba Village which is not in line with the Rights and Obligations of Land Tenure in the Gelgel Ancient Village are following the awig - awig of the Gelgel Purba Village. It is hoped that residents can be vigilant and follow what the Banjar Adat community has united.
\end{abstract}

Keywords: customary sanctions; land; utilization.

\begin{abstract}
Abstrak - Tanah bisa menjadi keinginan manusia yang sangat mendasar. hubungan antara manusia dengan tanah dapat berupa hubungan ilmu gaib non sekuler yang sedikit banyak mengandung bagian-bagian kekuatan gaib (mistis) sebagai perwujudan manusia dan alam sekitarnya. Teknik inkuiri dikendalikan oleh radio dengan teknik pengumpulan pengetahuan melalui wawancara langsung dengan orang-orang yang berkompeten teori viktimisasi receptie, receptio dalam teori yang rumit dalam konstruksi negara hukum untuk melihat fenomena kekinian dalam tatanan kehidupan masyarakat, khususnya di lingkungan Gelgel Desa Purba, Kabupaten Klungkung. Hasil penelitian menunjukkan bahwa penggunaan Tanah Pekarangan Desa di dalam Desa Purba Gelgel disewakan secara bebas oleh warga Desa Gelgel Pakraman kepada pihak yang berbeda. Sanksi Adat Krama Desa Purba Gelgel yang tidak sejalan dengan Hak dan Kewajiban Penguasaan Tanah Desa di dalam Desa Purba Gelgel, sesuai dengan awig - awig Desa Purba Gelgel. diharapkan warga dapat waspada dan mengikuti apa yang telah dipersatukan masyarakat Banjar Adat.
\end{abstract}

Kata Kunci: sanksi adat; tanah; pemanfaatan.

\section{Pendahuluan}

Tanah merupakan salah satu aset yang sangat mendasar bagi masyarakat di Bali, karena masyarakat tinggal dan berkembang di atas tanah. Orang-orang di Bali memposisikan tanah pada posisi penting karena itu adalah masalah terbesar. orang membaca tanah sebagai persediaan kehidupan manusia dari lahir sampai mati. Tanah digunakan sebagai areal untuk mengukur dan sebagai persediaan kehidupan manusia sep- erti menanam padi, jagung, sayur-sayuran. Selain fungsi sosial keagamaan, tanah desa juga memiliki fungsi ekonomi tingkat asosiasi. Lahan desa yang bergaya lahan pertanian telah lama digunakan untuk mendukung keinginan ekonomi warga desa dalam memoles aktivitasnya, terutama tanah desa yang bergaya pasar tanah atau lahan yang digunakan untuk berbagai fasilitas ekonomi, seperti disewakan agar keuntungannya dapat diperoleh. dan fungsi ekonomi sangat jelas. untuk penduduk desa sebagai satu 
kesatuan atau sendiri-sendiri.

Sebagai kualitas sosial, tanah dapat menjadi sarana pengikat kesatuan sosial antara masyarakat Indonesia untuk mengukur dan hidup, sedangkan sebagai kualitas modal, tanah dapat menjadi modal berpikir tentang pembangunan. Oleh karena itu, tanah tumbuh sebagai objek yang sangat diperlukan namun sebagai bahan iklan dan objek spekulasi. Secara hukum, hak atas tanah Desa Pakraman diakui oleh Negara. Pasal 18B ayat (2) UndangUndang Dasar Negara Republik Indonesia Tahun 1945 secara tegas mengakui hak-hak yang wajar dari kesatuan-kesatuan masyarakat hukum adat, serta hak-haknya atas tanah yang telah ada dan melekat sejak terbentuknya kesatuan masyarakat hukum adat. diakui bahwa keberadaan hak kesatuan masyarakat hukum adat atas tanah dianggap sebagai hak ulayat.

Pada tataran peraturan daerah, hak desa adat atas tanah secara tegas diakui dalam Perda Provinsi Bali nomor empat tahun 2019 bahwa Desa Purba sebagai kesatuan masyarakat hukum adat mendukung falsafah Tri Hita Karana yang dibekukan dalam pengetahuan asli Kerthi yang tidak bahagia, dijiwai dengan ajaran dan nilai- nilai Hindu non sekuler. Nilainilai budaya dan kearifan lokal yang mendiami Bali, memiliki peran yang sangat masif dalam pembangunan bermasyarakat, berbangsa dan bernegara, sehingga perlu dibina, dilindungi, dibina, dikembangkan, dan diberi wewenang agar dapat dipahami sepanjang hayat. Krama Bali yang berdaulat secara politik, lepas secara ekonomi, dan berwatak cerdas. dalam budaya. tanah adat atau tanah ulayat desa di Bali sebagaimana disebutkan di atas tanah nefrosis adalah tanah kebahagiaan bagi persekutuan hukum adat yang disebut desa adat yang pengelolaannya diberikan kepada krama desa dengan kewajiban desa serta segala kewajibannya. ke Kahyangan Desa, atau tanah desa Pakraman dikuasai langsung oleh desa Pakraman yang sama sekali berbeda dari masyarakat hukum adat yang berbeda.

Pemanfaatan terhadap Tanah Pekarangan Desa di Desa Adat Gelgel, dimana Tanah Pekarangan Desa (PKD) dan Ayahan Desa (AYDs) sebagai tanah adat banyak disewakan secara bebas oleh warga Desa Pakraman Gelgel kepada pihak lain, karena dengan awalnya yang tanah tersebut diberikan gratis oleh desa kepada masyarakat untuk ditempati dan ditinggali, tetapi dikarenakan karena susahnya mencari penghasilan maka masyarakat yang diberi tanah oleh desa adat banyak menyewakan terhadap orang lain untuk dimanfaatkan.
Sehubungan dengan kekurangan tersebut, Bapak I Wayan Sudiantara selaku Kepala Perbekel Desa Purba Gelgel, dalam wawancara rekanan pada Selasa, 9 Maret 2021 pukul 16.00 WITA, dengan tepat menyatakan bahwa Dalam bacaan biasa, tidak ada yang terbaca bahwa adat ketentuan harus berada di tengah kondisi yang menjamin kontrol sosial mereka dengan pendekatan pemaksaan eksploitasi, yang disebut sesat, khususnya hukum adat bukanlah hukuman . tangga yang berada di luar jalan tatanan kosmis agar tidak mengganggu tatanan kosmos.

Awig-awig yang dipatuhi terlampir dalam salah satu kewajiban warga desa demi jalannya Desa Kala, Patra. Dengan menaati atau menyelesaikan kewajibannya sebagai warga desa, masyarakat juga diberikan hak oleh desa, misalnya diberikan perlindungan dari desa kuno dan diberikan tanah desa bagi warga desa yang kurang mampu (Surpha, I Wayan, 2004 3). Dengan syarat bahwa masyarakat senantiasa mengalami dinamika, maka negara hukum bersama-sama dengan hukum adat harus mengikuti dinamika tersebut. Jika batas kelenturan sudah melewati batas, prinsipnya harus dimodifikasi, menyesuaikan dengan desa, kala, patra. (Sudyat Iman, 1981 27).

Dalam bacaan hukum adat, senada dengan jazzman Soesangobeng, dinyatakan bahwa tanah dan manusia memiliki hubungan yang sedemikian rinci, dan dalam jalinan pemikiran (participerend denken), agar hubungan antara manusia yang berasosiasi dengan tanah dapat menjadi suatu hubungan sihir non sekuler yang sedikit banyak mengandung bagian-bagian kekuatan gaib (mistis) sebagai perwujudan dialog antara manusia dan juga alam gaib, khususnya roh-roh yang mereka hargai (Herman Soesangobeng, 1975 51).

Pemanfaatan terhadap Tanah Pekarangan Desa di Desa Adat Gelgel, dimana Tanah Pekarangan Desa (PKD) dan Ayahan Desa (AYDs) sebagai tanah adat banyak disewakan secara bebas oleh warga Desa Pakraman Gelgel kepada pihak lain, karena dengan awalnya yang tanah tersebut diberikan gratis oleh desa kepada masyarakat untuk ditempati dan ditinggali, tetapi dikarenakan karena susahnya mencari penghasilan maka masyarakat yang diberi tanah oleh desa adat banyak menyewakan terhadap orang lain untuk dimanfaatkan.

\section{Metode}

Penelitian ini menggunakan jenis penelitian empiris, yang sebenarnya membutuhkan pengetahuan sekunder lebih lanjut dalam 
jenis bahan atau referensi hukum alternatif sebagai pengetahuan pendukung dari analisis sektor yang penulis lakukan. (Subagya Joko, 2013 29).

Dalam kaitannya dengan pendekatan materi, penulis menggunakan pendekatan ilmu sosial hukum dengan menganalisis dan menemukan hukum yang terkait dengan masalah hukum dalam analisis dalam jenis pemeriksaan aspek hukum dan juga pengaruh aturan. hukum dalam masyarakat, dengan mengutamakan pendekatan yuridis dan ilmu sosial terlebih lagi sebagai aspek ekonomi masyarakat.

Teknik pengumpulan data yang penulis gunakan dalam penelitian ini adalah Teknik wawancara atau interview yang patokan digunakan bagian dalam analisis empiris. Wawancara dibikin bukan sekedar bertanya ambang seseorang, memilih dilakukan pakai memasrahkan soal - soal yang tebakan dirancang pakai tersusun menjelang menggerapai reaksi reaksi yang relevan pakai pertanyaan yang terdapat bagian dalam analisis ini yang efektif menjelang mengulurkan kenyataan reaksi bersumber pokok bagian yang terdapat bagian dalam analisis yang klerek bikin, sedangkan bukti sekunder dilakukan pakai kupasan dokumentasi pakai taktik pencatatan.

Penelitian yang klerek bikin pakai menganalisa bukti-bukti yang dikumpulkan bersumber gelanggang atau jalan bentar kintil bukti -bukti pemeriksaan dan tertib perundangimbauan yang klerek bisa di corong elektronik pakai meninjau kintil memetakan bukti fokus, sekunder maupun tersier yang dijabarkan secara tersurat menjelang mengulurkan reaksi bersumber pokok bagian yang terdapat.

Teknik kupasan bija resam yang klerek gunakan adalah taktik pokok kupasan disamping itu juga klerek mengamalkan pendapat atau pemeringkatan bercorak betul atau tidak betul, sepaham atau tidak sepaham dan raja atau tidak raja bersumber analisis ihwal filsafat pokok adab resam yang terselip ambang bija resam fokus dan bija resam sekunder.

Untuk bersitegang tinjauan bersumber analisis ini klerek mengabdikan taktik relasi pakai dasar spesifik ihwal pendapat pertanyaan yang terdapat dan kulur bersandarkan ambang buktibukti yang berwatak intelek resam pakai pengertian atau dasar yang betul menjelang bersitegang dan memperlihatkan ketajaman intelek resam itu sendiri.

\section{Hasil Dan Pembahasan}

\section{Pemanfaatan terhadap Tanah Pekarangan Desa di Desa Adat Gelgel}

Tanah mungkin merupakan bagian dari planet yang memiliki arti yang sangat penting bagi manusia dalam menjalani kehidupannya. Awig-awig yang dipatuhi terlampir dalam salah satu kewajiban warga desa demi jalannya Desa Kala, Patra. Dengan menaati atau menunaikan kewajibannya sebagai warga desa, masyarakat juga diberikan hak oleh desa, misalnya diberikan perlindungan dari desa kuno dan diberikan tanah desa bagi warga desa yang kurang mampu. Dengan syarat bahwa masyarakat senantiasa mengalami dinamika, maka negara hukum bersama-sama dengan hukum adat harus mengikuti dinamika tersebut. Jika batas kelenturan sudah melewati batas, prinsipnya harus dimodifikasi, menyesuaikan dengan desa, kala, patra.

Dalam tata guna lahan di Desa Purba Gelgel, pada mulanya tanah ulayat desa atau tanah ulayat di dalam Desa Purba Gelgel dikuasai oleh desa biasa itu sendiri. Tanah ini terbagi menjadi 2 varietas, yaitu Tanah Desa Pekarangan (PKD), dan Tanah Tanah Asli Desa (AYDs). Tanah pekarangan desa (PKD) adalah tanah yang dikuasai oleh desa yang diberikan kepada adat desa dimana saja untuk dijadikan perumahan yang biasanya dalam ukuran ruang yang sangat pasti dan bersifat tetap di setiap keluarga. sedangkan Tanah Bapak Desa (AYDs) adalah tanah untuk pertanian atau lainnya yang juga diberikan kepada penduduk untuk dikelola dan dibuat untuk kebaikan hidupnya serta diimbangi dengan kewajiban terhadap desa. (Djoko Prakoso, Bambang Riyadi Lang, 1987 56).

Pemanfaatan terhadap Tanah Pekarangan Desa di Desa Adat Gelgel, dimana Tanah Pekarangan Desa (PKD) dan Ayahan Desa (AYDs) sebagai tanah adat banyak disewakan secara bebas oleh warga Desa Pakraman Gelgel kepada pihak lain, karena dengan awalnya yang tanah tersebut diberikan gratis oleh desa kepada masyarakat untuk ditempati dan ditinggali, tetapi dikarenakan karena susahnya mencari penghasilan maka masyarakat yang diberi tanah oleh desa adat banyak menyewakan terhadap orang lain untuk dimanfaatkan.

Awalnya, tanah ulayat desa atau tanah ulayat di lingkungan Desa Kuno Gelgel dikuasai oleh desa biasa sendiri. Tanah ini terbagi menjadi 2 varietas, yaitu Tanah Desa Pekarangan (PKD), dan Tanah Tanah Asli Desa (AYDs). Tanah pekarangan desa (PKD) adalah tanah yang dikuasai oleh desa yang diberikan kepada adat desa dimana saja untuk dijadikan perumahan yang biasanya dalam ukuran ruang 
yang sangat pasti dan bersifat tetap di setiap keluarga. sedangkan Tanah Bapak Desa (AYDs) adalah tanah untuk pertanian atau lainnya yang juga diberikan kepada penduduk untuk dikelola dan dibuat untuk kebaikan hidupnya serta diimbangi dengan kewajiban terhadap desa.

Sehubungan dengan kekurangan tersebut, Bapak I Wayan Sudiantara selaku Kepala Perbekel Desa Purba Gelgel, dalam wawancara rekanan pada Selasa, 9 Maret 2021 pukul 16.00 WITA, dengan tepat menyatakan bahwa Dalam bacaan biasa, tidak ada yang terbaca bahwa adat ketentuan harus berada di tengah kondisi yang menjamin kontrol sosial mereka dengan pendekatan pemaksaan eksploitasi, yang disebut sesat, khususnya hukum adat bukanlah hukuman . tangga yang berada di luar jalan tatanan kosmis agar tidak mengganggu tatanan kosmos.

Awig-awig yang dipatuhi terlampir dalam salah satu kewajiban warga desa demi jalannya Desa Kala, Patra. Dengan menaati atau menyelesaikan kewajibannya sebagai warga desa, masyarakat juga diberikan hak oleh desa, misalnya diberikan perlindungan dari desa kuno dan diberikan tanah desa bagi warga desa yang kurang mampu (Surpha, I Wayan, 2004 3). Dengan syarat bahwa masyarakat senantiasa mengalami dinamika, maka negara hukum bersama-sama dengan hukum adat harus mengikuti dinamika tersebut. Jika batas kelenturan sudah melewati batas, prinsipnya harus dimodifikasi, menyesuaikan dengan desa, kala, patra. (Sudyat Iman, 1981 27).

\section{Sanksi Adat terhadap Krama Desa Adat Gelgel yang Tidak Mentaati Hak dan Kewajiban Pengaturan Tanah Pekarangan Desa di Desa Adat Gelgel}

Penerapan sanksi dan awig-awig Desa Adat Gelgel sudah dilaksanakan secara turuntemurun. Salah satu bentuk penerapan sanksi dan awig-awig di Desa Adat Gelgel ialah larangan pengasingan (diasingkan dari Desa Adat seperti dilarang berbicara dengan warga yang diasingkan, dikeluarkan sementara dari banjar, dll). Pemanfaatan terhadap Tanah Pekarangan Desa di Desa Adat Gelgel, dimana Tanah Pekarangan Desa (PKD) dan Ayahan Desa (AYDs) sebagai tanah adat banyak disewakan secara bebas oleh warga Desa Pakraman Gelgel kepada pihak lain, karena dengan awalnya yang tanah tersebut diberikan gratis oleh desa kepada masyarakat untuk ditempati dan ditinggali, tetapi dikarenakan karena susahnya mencari penghasilan maka masyarakat yang diberi tanah oleh desa adat banyak menyewakan terhadap orang lain untuk dimanfaatkan.

Penerapan sanksi atas pelanggaran yang dilakukan oleh krama tidak lepas dari struktur struktur dan aturan (awig-awig) yang hidup untuk mendongeng tata krama desa (Soepomo, R, 1983 37). Hal ini juga berlaku bagi masyarakat hukum adat yang berbeda dalam penyelesaian perkara adat. Peranan Banjar Kelian atau Desa Purba yang dapat mengatur jaring awig-awig masa kini dan dapat menjadi pedoman yang sangat dominan dalam menjalankan pemerintahan desa adat.

Jika dilihat dari sanksi yang ada dan termuat dalam awig-awig, di mana pun ada aturan tegas yang mengikat setiap subjek atau tata krama desa adat, serta pelanggaran terhadapnya, sanksi dapat menjadi wajib. Dengan sanksi ini, masyarakat diharapkan mengadaptasi awigawig yang ada untuk kesejahteraan dan menghindari masyarakat dari sanksi yang dibuat atas kesepakatan bersama takdir Desa Gelgel. Awig-awig yang dipatuhi terlampir dalam satu kesatuan kewajiban warga desa demi jalannya Desa Kala, Patra.

Sehubungan dengan kekurangan tersebut, Bapak I Wayan Sudiantara selaku Kepala Perbekel Desa Purba Gelgel, dalam wawancara rekanan pada Selasa, 9 Maret 2021 pukul 16.00 WITA, dengan tepat menyatakan bahwa Dalam bacaan biasa, tidak ada yang terbaca bahwa adat ketentuan harus berada di tengah kondisi yang menjamin kontrol sosial mereka dengan pendekatan pemaksaan eksploitasi, yang disebut sesat, khususnya hukum adat bukanlah hukuman . tangga yang berada di luar jalan tatanan kosmis agar tidak mengganggu tatanan kosmos.

Awig-awig yang dipatuhi terlampir dalam salah satu kewajiban warga desa demi jalannya Desa Kala, Patra. Dengan menaati atau menyelesaikan kewajibannya sebagai warga desa, masyarakat juga diberikan hak oleh desa, misalnya diberikan perlindungan dari desa kuno dan diberikan tanah desa bagi warga desa yang kurang mampu (Surpha, I Wayan, 2004 3). Dengan syarat bahwa masyarakat senantiasa mengalami dinamika, maka negara hukum bersama-sama dengan hukum adat harus Selama masyarakat terus mengalami dinamika, maka supremasi hukum, serta hukum adat, harus mengikuti dinamika tersebut. Jika batas kelenturan telah melewati batas, maka pondasi harus diubah, menyesuaikan dengan desa, kala, patra

\section{Simpulan}


Pemanfaatan terhadap Tanah Pekarangan Desa di Desa Adat Gelgel, dimana Tanah Pekarangan Desa (PKD) dan Ayahan Desa (AYDs) sebagai tanah adat banyak disewakan secara bebas oleh warga Desa Pakraman Gelgel kepada pihak lain, karena dengan awalnya yang tanah tersebut diberikan gratis oleh desa kepada masyarakat untuk ditempati dan ditinggali, tetapi dikarenakan karena susahnya mencari penghasilan maka masyarakat yang diberi tanah oleh desa adat banyak menyewakan terhadap orang lain untuk dimanfaatkan.

Sanksi Adat terhadap Krama Desa Adat Gelgel yang tidak mentaati Hak dan Kewajiban pengaturan Tanah Pekarangan Desa di Desa Adat Gelgel, dimana sesuai dengan awig - awig Desa Adat Gelgel, sanksi dimaksud yaitu pada Pawos 22. Tan kepatutan ngadol utawi numbas pekarangan desa (tidak dibenarkan menjual atau membeli pekarangan desa). Yen wenten sinalih tunggil pawongan ngadol wewangunan ring pekarangan desa inucap patut tedun makrame desa (apabila ada seseorang menjual bangunan dalam pekarangan desa, maka pihak pembeli wajib menjadi anggota desa).

\section{Daftar Pustaka}

Herman, S. (1975). Pertumbuhan hak milik individual menurut hukum adat dan menurut UUPA di Jawa Timur. Majalah Hukum, No. 3 Tahun kedua, Yayasan Penerbitan dan Pengembangan Hukum (Law Centre).

Prakoso, D., Lang, B, R. (1987). Dasar Hukum Persetujuan Tertentu di Indonesia. Jakarta: PT. Bina Aksara.

Iman, S. (1981). Hukum A dat Sketsa A sas, Liberty, Cetakan kedua, Yogyakarta. Soepomo R, 1983, Hubungan Individu dan Masyarakat dalam Hukum Adat, Cetakan ke-4. Jakarta: Pradnya Paramita.

Surpha I, W. (2004). Eksistensi Desa Adat dan Desa Dinas di Bali. Denpasar: Pustaka Bali Post. 